\title{
Climate Change and Landslide Risk Assessment in Uttaradit Province, Thailand
}

\author{
Shotiros Protonga, Paul A. Carling ${ }^{\mathrm{b}}$, and Julian Leyland ${ }^{\mathrm{c}}$ \\ Geography and Environment at the University of Southampton \\ E-mail: ashotirosprotong@yahoo.com, bP.A.Carling@soton.ac.uk, cJ.Leyland@soton.ac.uk
}

\begin{abstract}
The incidents of sudden landslides in Thailand during the past decade have occurred frequently and more severely. The rain-triggered landslide hazard analysis is the focus of this research. The combination of geotechnical and hydrological data is used to determine permeability, conductivity, bedding orientation, overburden and presence of loose blocks. The regional landslide hazard mapping is developed using the Slope Stability Index SINMAP model supported on Arc GIS software version 10.1.

The geological data can indicate the shear strength and the angle of friction values for soils above given rock types, which leads to the general applicability of the approach for landslide hazard analysis. In terms of hydrological data, the millimetres/twenty-four hours of average rainfall data are used to assess the rain triggered landslide hazard analysis in slope stability mapping. The Statistical Downscaling Model (SDSM) version 4.2, is used to assess the simulation scenario of future change; the study area is Uttaradit province, northern Thailand. The landslide hazard mapping will be compared and shown by areas $\left(\mathrm{km}^{2}\right)$ for both present and future conditions under climate simulation scenarios A2 and B2 in Uttaradit province. The identified risk areas largely lie in hilly and mountainous terrain; which areas can be given additional protection during land use planning in order to reduce the risk of slope failure and the associated impacts on human activities.
\end{abstract}

Keywords: Landslide, Geotechnical data, Hydrological data, permeability, SINMAP, SDSM, etc.

ENGINEERING JOURNAL Volume 22 Issue 1

Received 14 September 2017

Accepted 28 October 2017

Published 31 January 2018

Online at http://www.engj.org/

DOI:10.4186/ej.2018.22.1.243

This article is based on the presentation at the THA 2017 International Conference on "Water Management and Climate Change towards Asia's

Water-Energy-Food Nexus" in Bangkok, Thailand, 25th-27th January 2017. 


\section{Introduction}

Landslide occurrences have been related to extreme rainfall events and changes in the monsoon, therefore climate change problems have been affecting global communities, with heavier rainfall causing severe landslides, floods or longer consecutive dry days causing severe drought which effect slope stability. Thailand also suffers from the effects of climate change. Landslides cause severe damage, including loss of lives, property, disruption of infrastructure and broader economic impacts. Landslides occur in several regions in the southern and the northern parts of Thailand, especially during the rainy season. Evidently, landslides are caused by intense rainfall in the hilly and mountainous terrains [1] but little additional information is available.

Rainfall occurrences are dependent on atmospheric circulation patterns which are driven by the El NiñoSouthern Oscillation (ENSO) and other patterns of variability. The relationship between the atmospheric circulation change and climate change can shift the storm tracks and the tropical sea-surface temperature patterns. The El Niño-Southern Oscillation is a coupled ocean-atmosphere phenomenon and involves warming of tropical surface water and ocean circulation. The Southern Oscillation leads to changes in the wind track, which affects tropically circulated precipitation. The global atmospheric circulation depends on the pattern of variability; this circulation is also associated with regional climate in each location in terms of the storm track, the pole-ward fluxes of heat, moisture and momentum. Furthermore, there are seasonal and longer time-scale effects leading to flooding, drought occurrence and other disasters [2]. The interaction between atmosphere and ocean circulation are linked with the El Niño-Southern Oscillation, leading to anomalies with the circulation and rainfall.

This study seeks to analyze how the occurrence of landsliding in Uttaradit province will respond under different modelled future emissions of greenhouse gases as indexed by both IPCC emission scenario A2 and B2. A series of scenarios for future greenhouse gas emission can be determined by the IPCC Special Report on Emissions Scenarios (SRES) [3] called "SRES scenarios". In this study, the SRES series comprise two scenario storylines: A2 and B2. The SRES scenario of the A2 storyline describes the development of economic growth and technological change at local and regional levels. On the other hand, the scenario of the B2 storyline refers to the local situation alone, in economic terms, social and environmental sustainability, including environmental protection and social equity [4]. Different precipitation values are evaluated under scenario simulations in both A2 and B2 for landslide analysis in terms of the landslide hazard mapping

The study assesses the parameters of landslide dynamics and indicates the trend of landslide occurrences and the regional landslide hazard mapping under simulation of climate change based on scenario A2 and B2, related to the threshold rainfall values, soil, slope and vegetation characteristics. This study should lead to reduced loss of life and property damage by providing early warning of the location of landslide hazard zones.

\section{Case Study}

Uttaradit province is located in the northern part of Thailand between latitude $17^{\circ} 48^{\prime}$ and $18^{\circ} 12^{\prime}$ north and between longitude $100^{\circ} 9^{\prime}$ and $101^{\circ} 5^{\prime}$ east (see Fig. 1). It has a total area of about 7,838 $\mathrm{km}^{2}$. It has borders with Phrea province in the north, and in the east, it is bordered by Laos, while, in the south, it is bordered by Pisanulok province and in the west, by Sukhothai province [5]. Uttaradit province, consists of nine districts: Muang, Laplea, Thapla, Nampat, Bankhok, Faktha, Thongsaenkhun, Phichai and Tron. The nine districts comprise approximately $7,838 \mathrm{~km}^{2}$. The terrain can be divided into three types: (i) plains in the river basin, (ii) plains in the mountain valleys and (iii) the high mountainous terrain. The elevations of approximately 50100 metres above sea level, are found largely in three districts: Laplea, Tron and Thongsaenkhun. Elevations of 100-400 metres lies in the hilly and undulating areas in the northern and the eastern parts of the province in three districts: Laplea, Nampat and Thongsaenkhun, and the high elevated terrain of 400-1000 metres is also in the northern and eastern parts of the provinces in six districts: Muang, Laplea, Thapla, Nampat, Faktha and Bankhok [5]. The highest point of elevation is about 1,749 metres which occurs in four districts: Thapla, Nampat, Faktha and Bankhok. The incidence of landslides is usually related to the slope angle in elevated terrain. The natural forests also have largely been replaced by agricultural areas, such as annual crops, orchards, rubber plantations and galangal oil in the steep hills. Thus deforestation is one factor related to landsliding, because the soil-binding effect of-root strength is lost by forest clearance. Another local factor is that several regional streams in the mountains are blocked by roads, so both deforestation and road building factors affect landslide occurrences in several regions of the province [5]. 


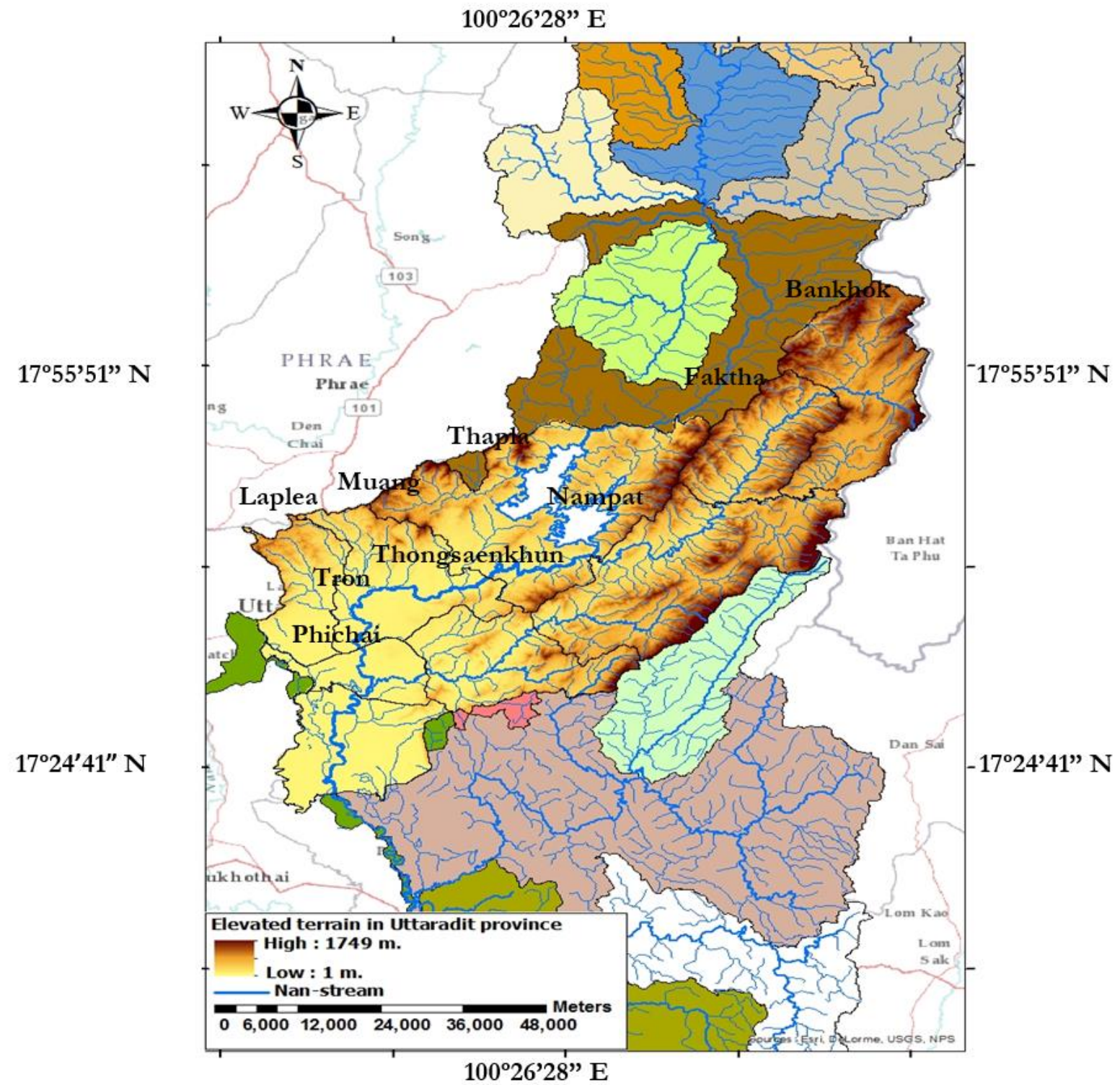

Fig. 1 Location of Uttaradit drainage basins in relation to surrounding basins. The locations of specific districts are also noted.

\section{Landslide Hazard Mapping Using SINMAP Model}

\subsection{Implementation of Stability Index Mapping (SINMAP)}

SINMAP software is a tool for terrain stability mapping and is based on infinite slope stability analysis. In this study, the SINMAP is applied to the issue of shallow translational landsliding within an Arc GIS 10.1 framework.

\subsubsection{The Stability Index (SI)}

a. High hazard classes (0.0-1.0), are defined with three SI value ranges, 0 (defended), 0-0.5 (upper threshold) and 0.5-1.0 (lower threshold) SI values of less than 1 would refer to failure regions.

b. Medium hazard classes (1.0-1.5), are defined with two SI value ranges, 1.0-1.25 (quasi stable) and 1.251.5 (moderately stable).

c. Low hazard classes $(>1.5)$ are defined as stable. 
The SINMAP model has been developed for use with Arc GIS version 9.0 or higher by computing the slope stability index. Based on the SINMAP approach, a combination of shallow ground water flow is applied to analyze only transitional shallow landslides. The infinite slope stability model is linked with saturated soil depths and pore water pressures which are balanced with the proportion of discharge in catchment areas. All key parameters can be calculated using the SINMAP model, such as specific catchment areas and quantitative soil properties, especially soil properties identified by soil cohesion and root cohesion values. The digital elevation model (DEM) can be determined in terms of topographic values including uncertainty values. The stability index equation was defined by SINMAP as follows [6]:

$$
F S=\frac{C+\cos \theta\left[1-\min \left(\frac{R a}{T \sin \theta}, 1\right) r\right] \tan \emptyset}{\sin \theta}
$$

\subsubsection{Model variables and model parameters}

The description of the SINMAP model requires four variable parameters as follows: $C$, (cohesion), $\varnothing$ (Internal friction angle), the ratio $R / T$ and $\varrho s$ (the soil density).

The variable parameter values are linked with the digital elevation model (DEM) to calculate the FS values for each pixel. An inventory of known locations of landslides is used for validating the model output.

\subsubsection{Landslide inventory points theme}

The landslide inventory points theme is a vector dataset used in order to calibrate the model. GPS technique is used to provide the geospatial position of the past landslide inventory points theme in four districts: Maung, Laplea, Thapla and Nampat [7].

\subsubsection{Geotechnical data: Cohesion and internal friction angle}

The characterization of local residual soils and land use using digital mapping in the six districts of Muang, Laplea, Thapla, Nampat, Bankhok and Faktha, was determined in the field during December 2013. The local residual soils data consisted of soil thickness, cohesivity, permeability and wet soil density values. Otherwise, the land cover/land use was surveyed and represented by vegetation type corresponding with the landslide occurrences, the root cohesion values were calculated for the species of vegetation types [8].

\subsubsection{Hydrological data: $R / T$ as required by the software}

The transmissivity $(T)$ of the hydrological data input is assigned as the vertical significant hydraulic conductivity of soil and is defined by:

$$
T=k s \times b
$$

where the $k_{s}$ value is the saturated permeability of the material of interest. The $k_{s}$ value is obtained using the American Standard Test Method (ASTM) in a geotechnical laboratory including soil thickness for calculation of transmissivity $(T)$ values. The $b$ is soil depth. The $R$ parameter in the SINMAP model is equivalent to the effective recharge for a critical period of wet weather linked with the trigger landslides and is given by:

$$
R=\text { Rainfall }- \text { Evapotranspiration }- \text { Deep Percolation }
$$

The evapotranspiration and deep percolation are negligible values to calculate during rainstorms causing landslides. Due to a steady heavy rainfall, the evapotranspiration and deep percolation would be minimal values as given for example by Fowze et al. (2012) [?].

\subsubsection{Digital Elevation Model (DEM) grid theme and pit filled DEM}

Based on Arc GIS software, the grid DEM is shown using a raster dataset where the elevation or slope angles may be represented in digital maps of the study areas. In this study, the grid DEM at a 30 metres resolution was 
downloaded from mmn.gdem.ersdac.jspacesytems.or.jp/ and each pixel represents 30 metres on the ground. The output of SINMAP is mapped and defined for the areas of potential terrain instability. The combination of SINMAP Arc map toolbar and an Arc map document within GIS create and display the topographic grid data. Then, the topographic basis of SINMAP was defined by a DEM grid. The grid of soil and hydrological terrain parameters were classified for calibration regions. An overview of the work plan is shown (see Fig. 2).

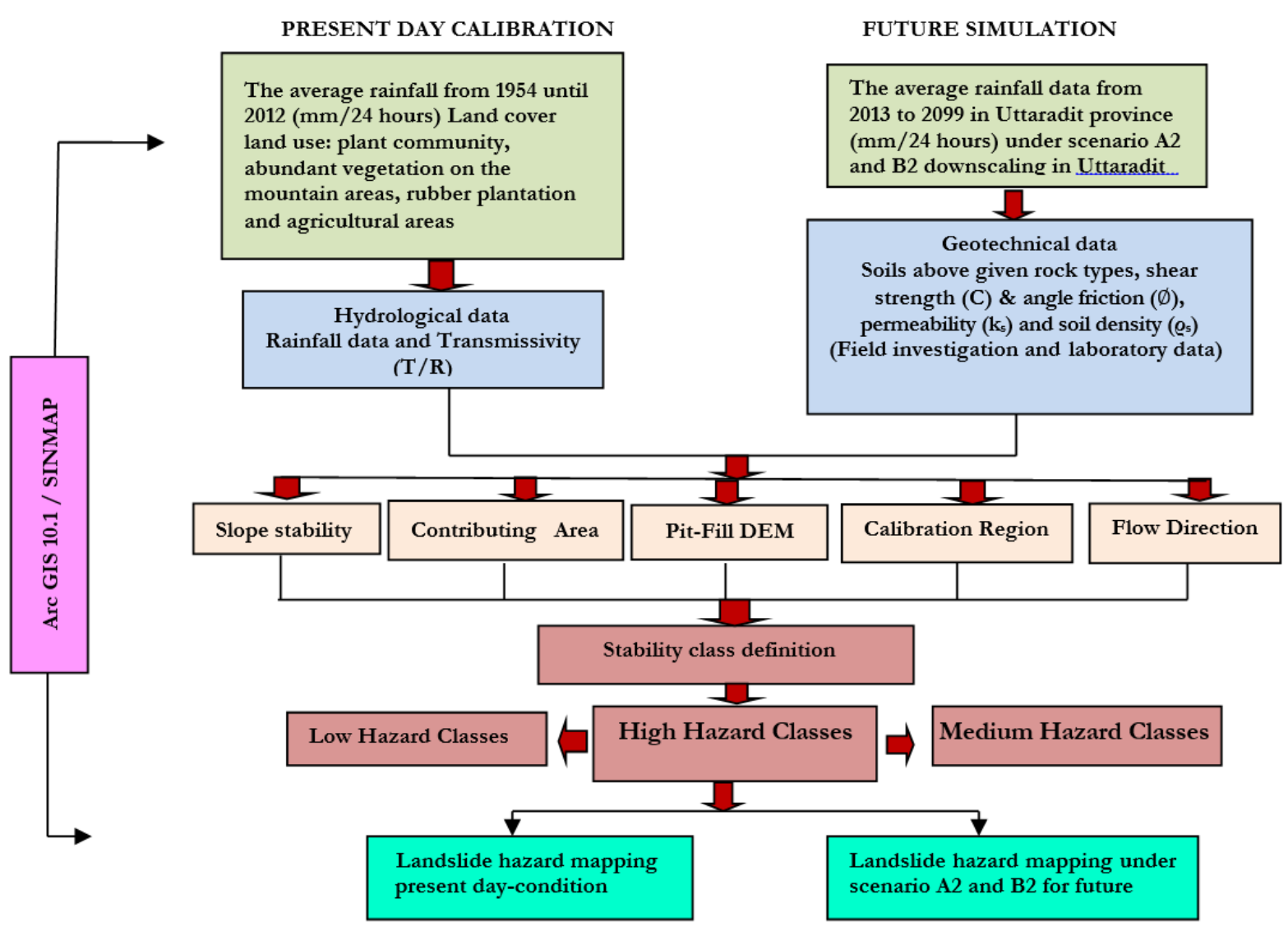

Fig. 2. Conceptual framework for the project.

\subsection{SINMAP Model Calibration}

In the study area, several parameters are used to regionalize the geology and the land use in the digital mapping data. The geotechnical parameters characterize the slope stability due to the contribution of root and soil cohesion values. The reclassification of land use is grouped by various land use types, such as slash-and-burn agriculture, rubber plantations, annual crops, galangal oil, orchards and bare lands which were surveyed by the author during

December 2013. Whereas, the reclassification of vegetation was grouped by the species of vegetation types, and the root cohesion values referred to by Nilaweera (1994) [8].

As for the SINMAP, variable geotechnical parameters were initially used such as the saturated permeability, strength tests, internal friction angle and soil classification. The corresponding susceptibility classes between the landslide scars and the result of the SINMAP model were compared for model calibration. To provide samples for the geotechnical laboratory analyses, three test pit sample locations in Laplea and Thapla districts were selected according to past landslide occurrences. One test pit was excavated in tambon Maephun in Laplea district and two test pits were excavated in tambon Nam Man in Thapla district because of the past landslide occurrences in 2006. A multi region polygon theme was, accordingly, divided by geological group and soil type. The permeability and the soil density were obtained from consolidate drained (CD) sample as were the shear strength and the angle of friction. In terms of the direct shear test, a consolidation stage was provided for estimating a suitable time of failure, so the rate of displacement related to the coefficient of 
consolidation. A consolidate drain (CD) technique requires that the consolidation is completed and the pore water pressure changes during shear are prevented by allowing draining.

The complete set of parameters for the predictions are considered as equivalent to the apparent soil depth $(\mathrm{m})$, the soil density $\left(\mathrm{kg} / \mathrm{m}^{3}\right)$, the root cohesion $(\mathrm{KPa})$, the soil cohesion $(\mathrm{KPa})$, the angle of friction, the combined cohesion $(\mathrm{KPa})$, the hydraulic conductivity $(\mathrm{cm} / \mathrm{sec})$, the transmissivity $\left(\mathrm{m}^{2} /\right.$ day), the recharge $(\mathrm{m} /$ day) and $T / R(m)$. The basis of SINMAP consists of the infinite slope stability and topographic wetness index and is defined by the stability index (SI). SI means the factor of safety that is a measure of the destabilizing factor (effectively increased wetness). Thus, the consolidate drain (CD) technique is consistent with the assumption of SINMAP which includes the increased saturated trend and wetness index model [10].

\subsection{Sensitivity Analysis in SINMAP Model}

The sensitivity of the SINMAP model is an important part in the probability of landslide assessment. The uncertainty and sensitivity of parameters are computed for each pixel and shown by areas $\left(\mathrm{km}^{2}\right)$ Furthermore, the assessment of the sensitivity analysis directly affects the outcome of the model. The ranges of sensitivity of SINMAP parameters are calculated for the determination of the probability of stability assessment. The rain-triggered landslide hazard analysis was actualized by the relationship between the hydrological and the geotechnical parameterizations. Thus, the sensitivity analysis of the slope stability index model was undertaken by utilizing combined geotechnical and hydrological data. Six parameters were described, analyzed and manipulated by sensitivity analysis. In terms of geotechnical data, (1) dimensionless cohesion, (2) angle of friction, (3) the variability of soil depth, (4) permeability, and (5) the effective recharge (rainfall values) in hydrological data were presented. The sensitivity of (6) slope angle was derived from the digital elevation model (DEM) and linked with the sensitivity index of the Slope Stability Index (SINMAP) model.

\subsection{Calibration of Present Day Conditions}

Average annual daily rainfall data are used herein during the 1954-2012 period as recorded by the Thailand Meteorological Department (TMD) in Uttaradit province. Rainfall distribution is described by calculation using nine rain stations covering eleven provinces of Uttaradit: Tak, Pisanulok, Khon Kean, Udontani, Lampang, Petchaboon, Phrae, Loei, but there are no complete rainfall values in two rain stations in Sukhothai and Nong Bao Lum Phu. There are nine rain stations which related to the downscaling of the daily precipitation scenario in the future simulation from latitude $16^{\circ} 26^{\prime}$ and $18^{\circ} 37^{\prime}$ north and between longitude $98^{\circ} 52^{\prime}$ and $103^{\circ} 05^{\prime}$ east in SDSM software.

\subsection{The Result of Downscaled Future Climate of Precipitation (Future Simulation)}

The General Circulation Model (GCM) describes the relationship between the rising concentrations of greenhouse gasses and climate conditions at a global and regional scale. However, the GCM cannot extend to describe climate change conditions at the local scale, as it displays at too coarse a spatial resolution. Therefore, the simulation of the Regional Climate Model (RCM) is useful to assess the impact of climate change at the local scale. For climate change in Thailand, the future climate scenarios are simulated at both spatial and temporal scales. The precipitation input is needed to predict for future climate, and the Statistical Downscaling Model (SDSM), was used to assess the simulation scenario of future change for latitude 16 $26^{\prime}$ and $18^{\circ} 37^{\prime}$ north and between longitude $98^{\circ} 52^{\prime}$ and $103^{\circ} 05^{\prime}$ east in the SDSM software. Rainfall distribution is described by calculation using nine rain stations covering eleven provinces of Uttaradit. The baseline period of observed daily rainfall data (mm) 1961-1990 was generated for SDSM calibration for each of the nine central rain stations.

For the period 1961-2012, observed rainfall was a baseline for calibration in SDSM and START software covering nine rain stations in the nine provinces of Uttaradit, Pisanulok, Loei, Tak, Khon Kaen, Phrae, Udontani, Lampang and Petchaboon in the northern and northeastern parts of Thailand between latitude $16^{\circ} 26^{\prime}$ and $18^{\circ} 37^{\prime}$ north and between longitude $98^{\circ} 52^{\prime}$ and $103^{\circ} 05^{\prime}$ east (see Fig. 3). This Phrae Lampang Uttaradit Loei Udontani Tak Pisanulok Petchaboon Khon Kaen ensemble was used to compare observed and modelled annual rainfall during the 1961-2099 period for both climate scenarios A2 and B2. The SDSM output, derived from the HadCM3 model, was chosen for precipitation prediction during the period 1961 2099 under simulation scenarios A2 and B2, whilst, the climate change data in Southeast Asia are assessed by 
the Southeast Asia START Regional Centre, especially the precision of software, PRECIS and GCM datasets are downscaled in a regional climate model [11].

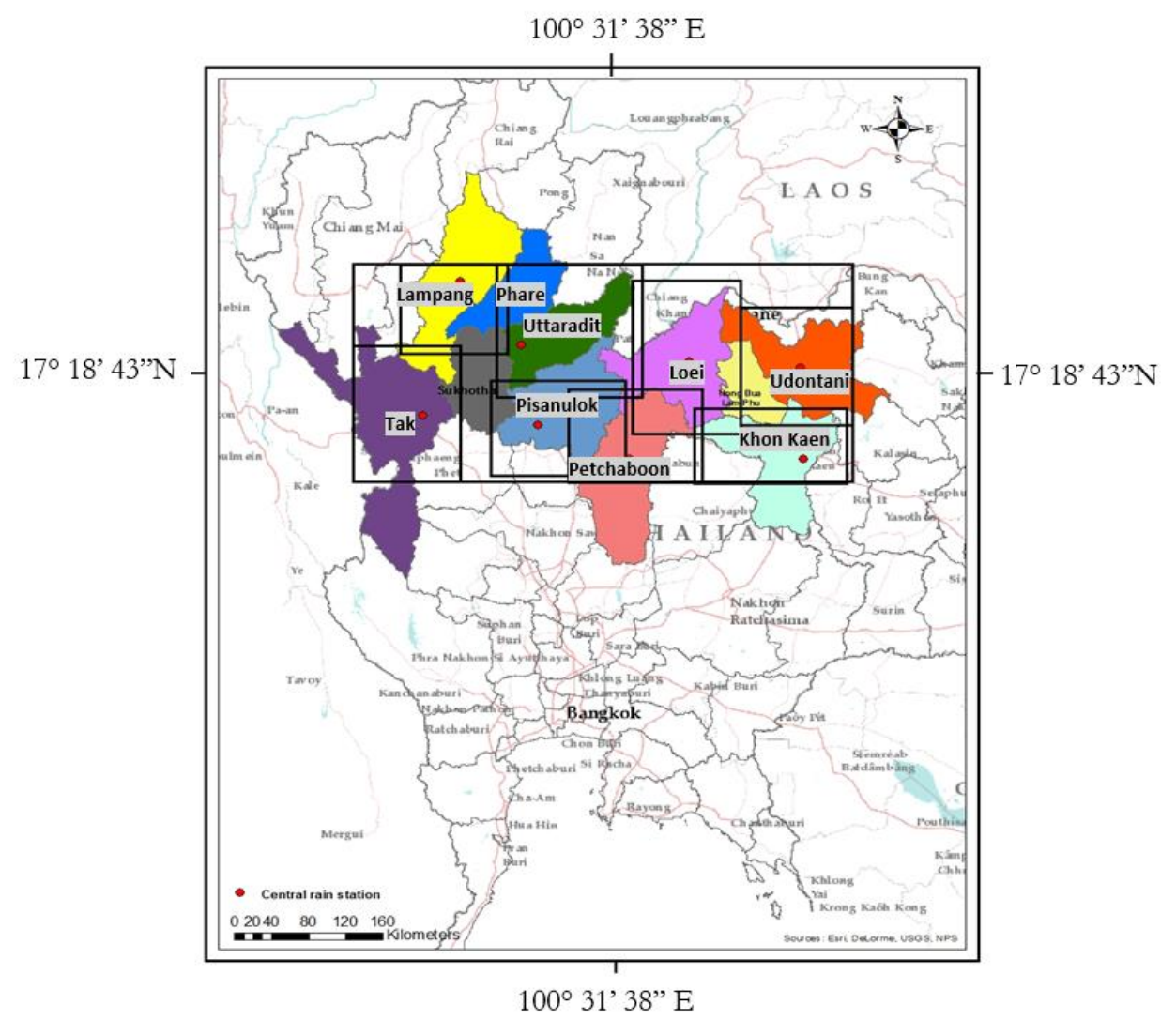

Fig. 3. Latitude and longitude in each province covering nine provinces by SDSM and START.

During the period of 2013-2099, the annual precipitations of climate scenario A2 and B2 were represented by a graph for both SDSM and START. The average of observed annual rainfall volumes during 1961-2012 and the annual modelled rainfall volumes, both SDSM in simulation scenario A2 and B2 and START in simulation scenario A2 and B2, during 1961 - 2099 are presented by a graph covering nine rain stations (see Fig. 4).

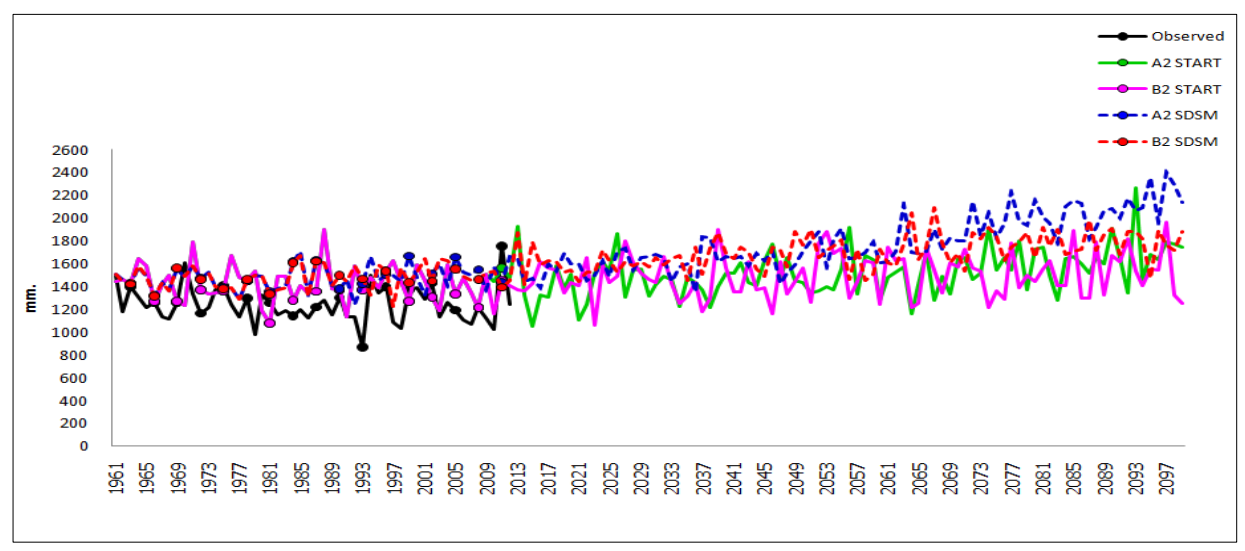

Fig. 4. Observed annual rainfall during 1961-2012, and the predicted annual rainfall quantities, both START in scenario A2 and B2 and SDSM in scenario A2 and B2 (five lines in the graph), during 1961-2099 covering nine rain stations. 
The comparison between observed and modelled rainfall: SDSM and START presented approximately $3.78 \%$ and $5.35 \%$ difference from 1961 to 2012 respectively.

\section{Calibration and Sensitivity of SINMAP Model}

The first section presents the setup and calibration of the SINMAP model through comparison between landslide areas of the SINMAP output and past landslides in 2006 in Laplea and Thapla districts in Uttaradit province. The second section describes analysis of the sensitivity of the SINMAP model parameters: dimensionless cohesion, angle of friction, soil thickness, permeability, rainfall and slope angles; which are varied and output is shown by the zonation of hazard classes $\left(\mathrm{km}^{2}\right)$.

\subsection{Calibration of SINMAP Model}

The landslide scar areas in both tambon Meaphun in Laplea district and tambon Namman in Thapla districts were presented for the SINMAP calibration under observed rainfall conditions in 2006, the landslide scars overlapped with three hazard classes: high, medium and low and also overlapped slope gradients of steep slopes, low slopes and flats. The high percentages of landslide scar areas overlapped with high and medium hazard classes and both steep slopes and low slopes. On the other hand, the low percentages overlapped with the low classes and flats. When the past landslide occurred, soil mass moved downward along a roughly planar surface. The failure covered several kilometres, so the low hazard class (safety areas) and slope gradients of $0^{\circ}-10^{\circ}$ (flat) were found in the lower landslide scar and runout areas.

As for the calibration in two tambons, approximately $80.15 \%$ of SINMAP output (averaged by adding the percentage of both high and medium classes in two tambons) and 86.5\% slope gradients (averaged by adding the percentage of both steep slopes and low slopes in two tambons) were presented as above. This result means that both high and medium classes and steep slopes and low slopes are linked to each other. These two percentages can confirm the efficiency of the SINMAP model, that it is suitable for landslide analysis. Therefore, in this study, the zonation of landslide risk should cover all areas of high and medium classes, and cover about, $19.85 \%$ of low class areas (percentage remaining i.e. (100-80.15)).

\subsection{Sensitivity of SINMAP Model}

As for the sensitivity of SINMAP parameters, the slope gradients were known throughout Uttaradit and five SINMAP parameters: dimensionless cohesion, angle of friction, soil depth, permeability and rainfall were presented for the Thapla district. There are five main parameters: slope gradients, dimensionless cohesion, angle of friction, permeability and rainfall.

As for sensitivity, the high hazard class areas increase from 186.5 to $362.2 \mathrm{~km}^{2}$ when rainfall values increase values from 50 to $300 \mathrm{~mm} /$ day, on the other hand the high hazard class areas decrease from 236.4 to $0 \mathrm{~km}^{2}$, when the range of dimensionless cohesion increases from $0-0.25$ to $1-1.5$. In terms of angle of friction, the high hazard class areas decrease from 1,224 to $120 \mathrm{~km}^{2}$, when the range of angle of friction increases from $5^{\circ}-10^{\circ}$ to $35^{\circ}-45^{\circ}$. The high hazard class areas increase from 136.7 to $628.7 \mathrm{~km}^{2}$ when permeability values decrease from E- 04 to E- $05 \mathrm{~cm} / \mathrm{sec}$. The four parameters relate to landslide susceptibility and SINMAP theory, including slope gradients. The reason, as analyzed above, is that the regression of four parameters is shown in high hazard class areas. Regression analysis is used to show the correlation in terms of linear regression. As described in the graph, the regression of the relationship of high class areas and the main four parameters: dimensionless cohesion, angle of friction, permeability and rainfall are presented. The regression between rainfall values and high class areas has a regression $\mathrm{r}^{2}=0.99$ for SINMAP model (see Fig. 5), on the other hand the regression between high class areas and all three parameters: dimensionless cohesion, angle of friction, permeability have negative slopes. The value of the correlation coefficient both rainfall and angle of friction are good $\left(\mathrm{r}^{2}=0.99\right)$, and higher than other parameters. The correlation coefficient of dimensionless cohesion and permeability are presented: $\left(\mathrm{r}^{2}=0.75\right)$ and $\left(\mathrm{r}^{2}=0.57\right)$. The reason, as analyzed above, is that five parameters are sensitive for landslide analysis in SINMAP model, while the most important are slope gradients and rainfall. 

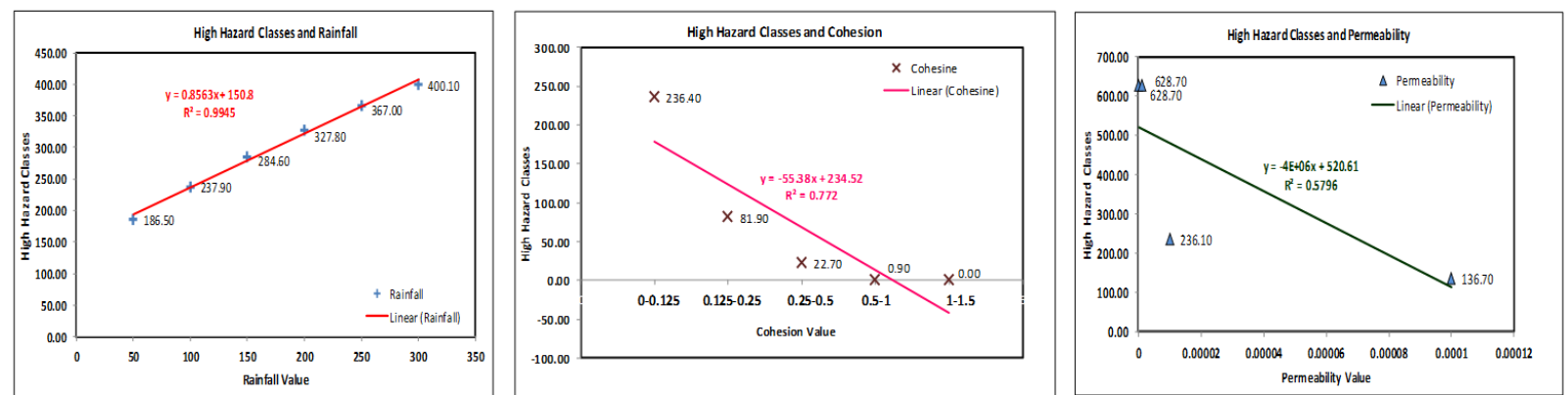

Fig. 5. Correlation coefficient of rainfall permeability and dimensionless cohesion related to the high hazard class areas $\left(\mathrm{km}^{2}\right)$ (failure regions).

\section{The Result of Landslide Hazard Mapping Comparing Present-Day Conditions and Future Simulation}

This result is divided into three sections. The first section describes the landslide hazard mapping for the present-day conditions in Uttaradit province, calculating rainfall values from 1954 to 2012. Then in the second section, the landslide hazard mapping in the future simulation during 2013-2099 will be forecast by SDSM program version 4.2 and START. Finally, the comparison of zonation of landslide risk $\left(\mathrm{km}^{2}\right)$ in the landslide hazard mapping, between both the calibration of present-day conditions and the future simulation, are presented by SINMAP software on Arc GIS version 10.1.

The relationship between the three hazard classes and three slope gradients were presented for each district. The zonation of landslide risk presented in all areas of high and medium classes and $19.85 \%$ of low class areas and also classified as steep slope, low slope and flat areas in nine districts: Muang, Thapla, Laplea, Nampat, Thongsaenkhun, Faktha, Bankhok, Tron and Phichai. The three-dimensional representation of slope gradients and mountainous areas are shown (see Fig. 6). Steep slopes, low slopes and flats presented in three hazard classes: high, medium and low (see Figs. 7-8).
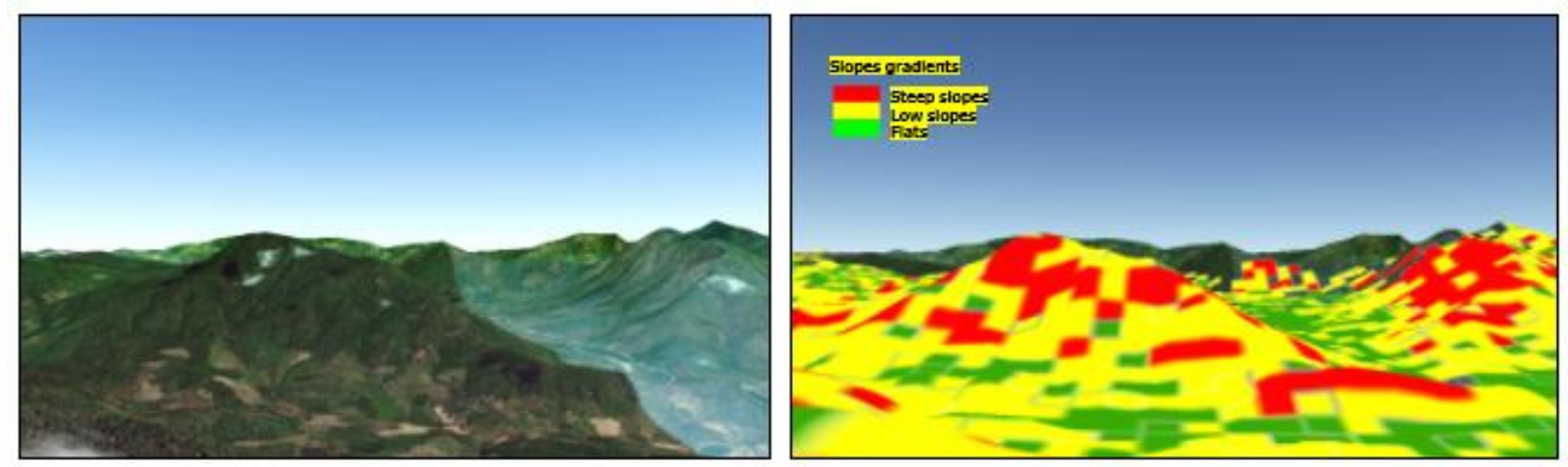

Fig. 6. Three-dimensional representation of real hilly and mountains by google earth showing the mixture of steep slopes, low slopes and flats between latitude 17o 45' 57" north and longitude 100o 13 ' 35" east. 

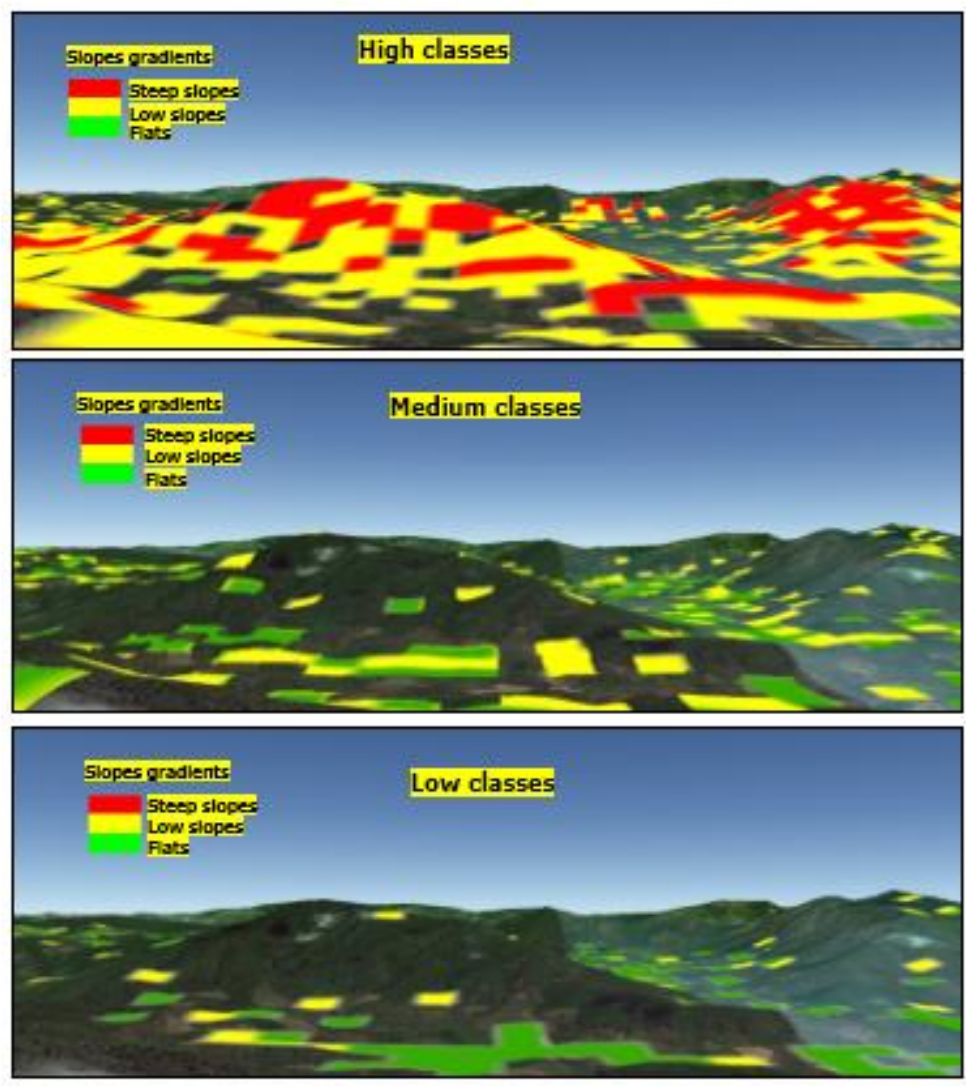

Fig. 7. Comparison between steep slope, low slope and flat areas showing in the high, medium and low hazard classes in three-dimensional representation of hilly and mountainous areas.

The zonation of landslide risk between present-day conditions and future simulation present in steep slope, low slope and flat areas in each district. The increasing rainfall in the future, most steep slope and low slope areas occur in high hazard classes, and then it will occur in medium and low classes respectively. Some parts of steep slopes and low slopes remained showing in medium and low classes. Most of flats were found in low classes. The high class areas will increase, while the medium and low class areas decrease when rainfall increase. Therefore, the increasing rainfall lead to the situation of instability (medium classes), becoming failure regions (high classes) and the situation of safety areas (low classes), becoming instability (medium classes). Therefore, rainfall is quite important for failure in both steep slope and low slope areas. Finally, the comparison of landslide risk and rainfall under present-day conditions and in the future simulation increases, showing in each district. The zonation of landslide risk is nearly the same between the present and in the future simulation. On the other hand, the increase of rainfall in the future will increase the high hazard class areas (failure regions), especially in steep slope areas, while the medium and low hazard class areas will decrease. Some areas of medium and low hazard classes become the high hazard class areas in steep slopes, low slopes and flat areas respectively. Thus, the increase of rainfall directly relates to the increase of landslide risk (failure region) in each district, while characteristics of soil (cohesive soil and permeability) also affect the risk areas.

\section{Discussion}

\subsection{SINMAP and Quantitative Analysis}

The high hazard class area (failure region) was compared with the landslide scars in tambon Maephun in Laplea district and in tambon Namman in Thapla district. The high hazard class area (failure region) and the landslide scar were very different. The potential failure region covered more area than just the landslide scar. The failure region in tambon Maephun in Laplea district is about $41.04 \mathrm{~km}^{2}$, while the landslide scar is approximately $26.8 \mathrm{~km}^{2}$. In tambon Namman in Thapla district, the failure region is approximately $139.8 \mathrm{~km}^{2}$, while the landslide scar is only approximately $13.1 \mathrm{~km}^{2}$. The difference between the failure region and the 
landslide scar are presented. The failure region was bigger than the landslide scar because the rainfall occurred in some parts of the mountains in the past. Orographic rain is associated with the elevation of mountains, when the moist air rises over the mountain and it rains on the windward side. However, the result showed that the zonation of landslide risk and slope gradient areas was linked with each other.

The zonation of landside risk should be compared with the areas of slope gradient. The result shows that the zonation of landslide risk and slope gradient areas is linked to each other. The zonation of landslide risk is calculated by adding $100 \%$ of both high and medium hazard classes and $19.85 \%$ of low hazard class, while slope gradients are also calculated by adding $100 \%$ of both steep and low slope areas and $19.85 \%$ of flat areas. Both the zonation of landslide risk and slope gradients presented in tambon Maephun in Laplea district: 88.6 $\mathrm{km}^{2}$ and $109.8 \mathrm{~km}^{2}$ respectively and in tambon Namman in Thapla district: $180.1 \mathrm{~km}^{2}$ and $210.4 \mathrm{~km}^{2}$. Therefore, the percentage of risk is $80.7 \%$ in tambon Maephun in Laplea district and $85.6 \%$ in tambon Namman in Thapla district. It means that the SINMAP output (the zonation of landslide risk) is linked with the slope gradients in both tambon Maephun in Laplea district and in tambon Namman in Thapla district.

\subsection{The Dominant Parameters: Slope Gradients and Rainfall}

Three slope gradients: steep slopes, low slopes and flats are related to three hazard classes: high, medium and low. Increase of rainfall from 50 to $300 \mathrm{~mm} / 24$ hours is dominant for increasing the high hazard classes on three slope gradients: steep slopes, low slopes and flats. Then, the areas of steep slope decrease, while low slope and flat areas increase in the medium hazard classes. All three slope gradient areas decrease in the low hazard classes. First the high hazard class areas occurred in steep slope areas, and then in low slope and flat areas respectively, when high class areas increased. The medium class areas occurred in the steep slope, low slope and flat areas that remained from the high classes. When the high class areas increased, the high class areas covered some parts of medium class areas. The medium class areas covered some parts of low class areas, and then low class areas decreased. The failure region increases in all three slope gradient areas: steep slope, low slope and flat areas when rainfall increases from 50 to $300 \mathrm{~mm} / 24$ hours.

\subsection{Dimensionless Cohesion and Angle of Friction}

In addition, the behaviour of dimensionless cohesion values (shear strength $\&$ root strength) directly affected the low hazard classes (safety area). Increased dimensionless cohesion ranges could reduce high (failure region) and medium (instability) class areas in hilly and mountainous areas, becoming low hazard class areas (safe). The dimensionless cohesion values of 0.5-1.0 present for safe areas (low hazard classes) in the hilly and mountainous terrains. For example, shallow roots of annual crops in agricultural areas $(1.10 \mathrm{kPa}$ of root strength value) and bare land (0 kPa of root strength value) are found in land cover/land use areas. On the other hand, with roots both in the horticultural area (slash-and-burn agriculture, annual crops and galangal oil) and teak (semi-natural and forest plantation (mainly teak) on the mountain areas $(1.10-2.94 \mathrm{kPa}$ of root strength value) cover all areas of land cover/land use areas. Approximately $82.8 \%$ of steep slope areas, $30.2 \%$ of low slope area and $0.47 \%$ of flat areas present for failure regions both with root and without roots $(0-$ $1.10 \mathrm{kPa}$ ), while approximately $55.9 \%$ of steep slope areas, $6.52 \%$ of low slope areas and $0.01 \%$ of flat areas present for failure regions with roots in all areas $(1.10-2.94 \mathrm{kPa})$. Therefore, the failure regions $\left(\mathrm{km}^{2}\right)$ on three slope gradients: steep slopes, low slopes and flats can be reduced on slopes because roots cover all areas of hilly terrain.

\subsection{The Relationship between the Trends of Rainfall and Slope Gradients in Three Hazard Classes in the Future}

This result show the correlation between three hazard classes and rainfall conditions in each five years periods from 2013 to 2099. Regression analysis is used to show the correlation in linear terms. It can be seen that the trend of the four simulations is similar among all regressions between three hazard classes and rainfall values. The trend of the four simulations among all regressions between the high hazard classes and rainfall values is positive, while the trend of the four simulations among all regressions between the medium and low hazard classes and rainfall values is negative.

These results mean that the increasing rainfall leads to the situation of instability (medium classes), becoming failure regions (high classes) and the situation of safety areas (low classes), becoming unstable (medium classes). The slope gradients: steep slopes, low slopes and flats in three hazard classes: high, medium and low are linked to 
each other. The correlation coefficient of three slope gradients: steep slopes, low slopes and flats in high hazard classes and rainfall is positive, while the correlation coefficient of three slope gradients: steep slopes, low slopes in medium hazard classes and rainfall is negative. The correlation coefficient of flats in medium hazard classes and rainfall is positive. In low hazard classes, the correlation coefficient of all three slope gradients: steep slopes, low slopes and flats is negative (see Figs. 8-10).

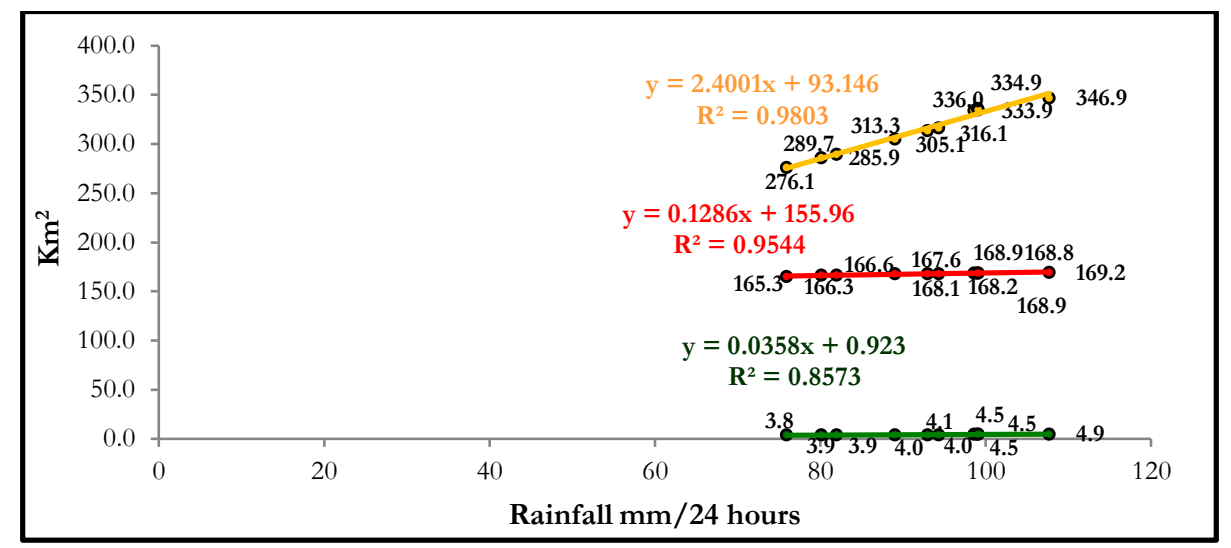

Fig. 8. The correlation of three slope gradients: steep slopes, low slopes and flats in the high hazard classes.

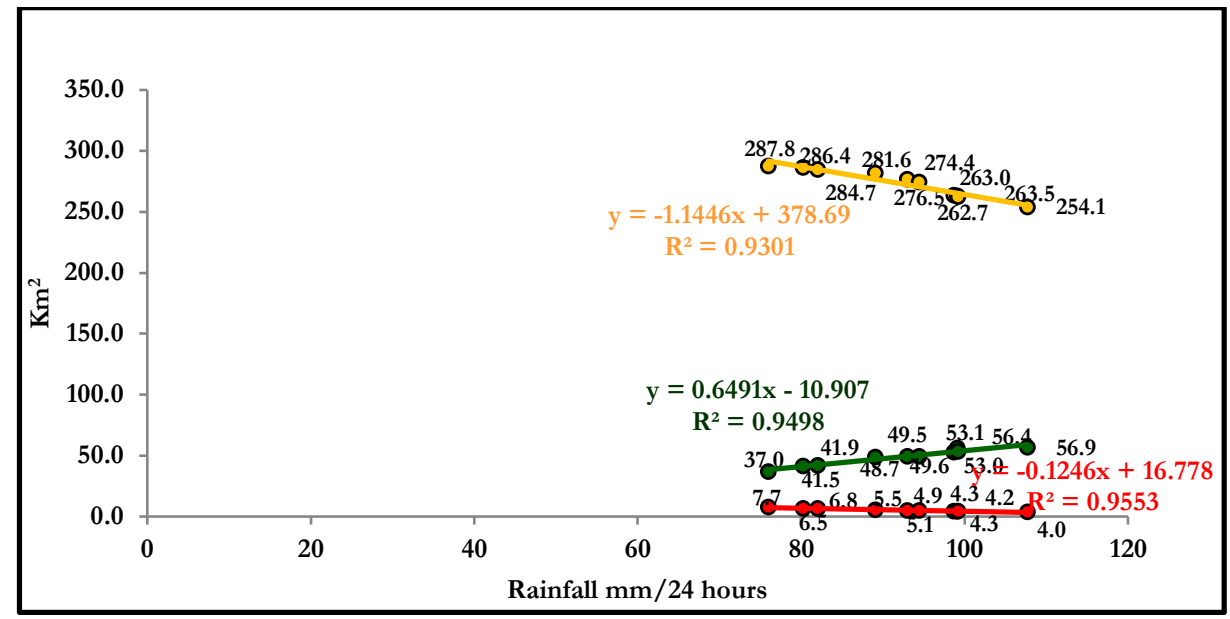

Fig. 9. The correlation of three slope gradients: steep slopes, low slopes and flats in the medium hazard classes.

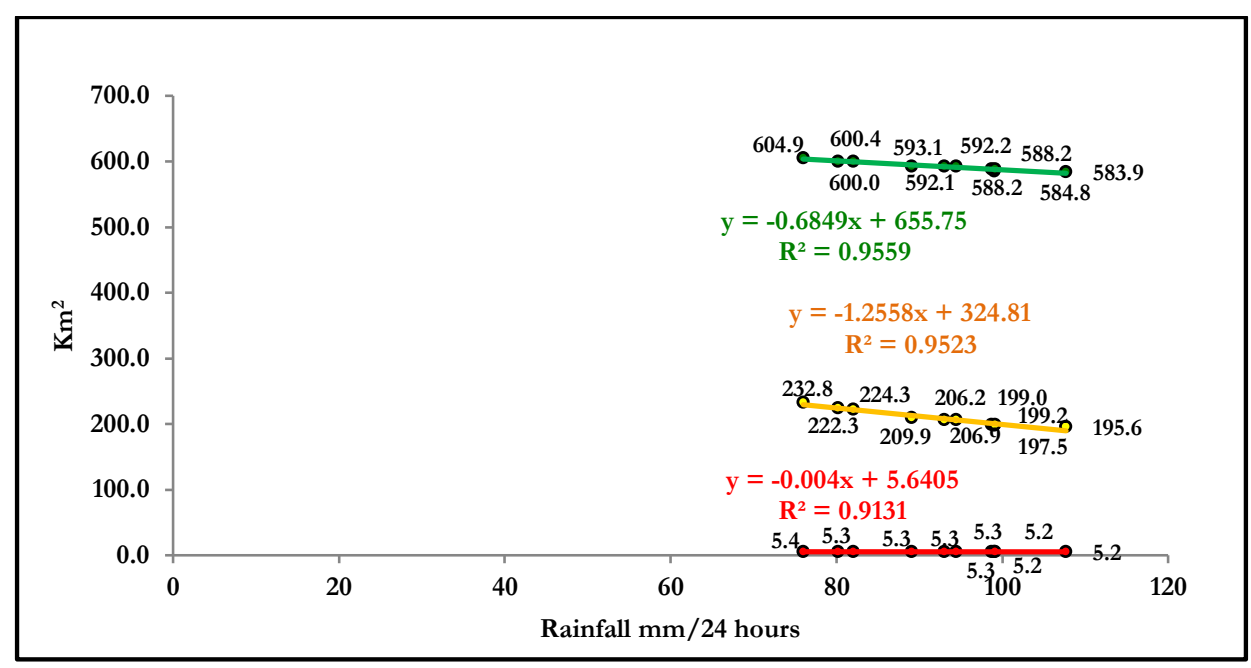

Fig. 10. The correlation of three slope gradients: steep slopes, low slopes and flats in the low hazard classes. 


\section{Conclusion}

The zonation of landslide risk in the future has been predicted for Uttaradit province. The increase of rainfall is presented in the future simulation. The change in rainfall condition in each district is used to analyze the landslide risk both present-day conditions and in the future simulation. So, the zonation of landslide risk is presented in the hilly and mountainous terrains in each district. The zonation of landslide risk $\left(\mathrm{km}^{2}\right)$ in three slope gradients: steep slopes, low slopes and flats increase in all nine districts in Uttaradit province. The increase of rainfall leads to increase the risk of landslide, especially the instability becomes the failure region in steep slope areas. The role of climate change affects the increase of rainfall, which lead to increase the landslide risk in hilly terrains.

This is useful for land use planning, not only in Thailand but a similar approach could be used-in other countries at risk. Because there has been a lot of deforestation for agriculture in the mountain areas landslide risk is increased. Deep tree roots reduce landslides so use of rooted crops or agroforesty will reduce landslide risk. It would be good for future research to develop real-time forecasting for landslide likelihood during and after heavy rainfall, so that the people living around the mountains can be forewarned, and evacuation considered where appropriate.

\section{Acknowledgements}

I would like to say thanks to the Office of the Civil Service Commission (OCSC) for funding me in the PhD course in UK, and thanks to Department of water resources to support me for this public paper.

\section{References}

[1] DMR (Department of Mineral Resources) Thailand, "The statistical threshold value of rainfall with landslide occurrences, Thailand," (in Thai), 2012.

[2] IPCC, Climate Change 2007: The Physical Science Basis. Contribution of working Group I to the Fourth Assessment Report of the Intergovernmental Panel on Climate Change, S. Solomon, D. Qin, M. Manning, Z. Chen, M. Marquis, K. B. Averyt, M. Tignor, and H. L. Miller, Eds. Cambridge, UK; New York, NY, USA: Cambridge University Press, 2007, pp. 608-631.

[3] N. Nakicenovic, J. Alcamo, G. Davis, B. de Vries, J. Fenhann, S. Gaffin, K. Gregory, A. Grübler, T. Y. Jung, T. Kram, E. L. La Rovere, L. Michaelis, S. Mori, T. Morita, W. Pepper, H. Pitcher, L. Price, K. Raihi, A. Roehrl, H. H. Rogner, A. Sankovski, M. Schlesinger, P. Shukla, S. Smith, R. Swart, S. van Rooijen, N. Victor and Z. Dadi, 2000: IPCC Special Report on Emissions Scenarios, Cambridge, UK; New York, NY, USA: Cambridge University Press, 2000.

[4] J. Houghton, Global W arming. New York: Cambridge University Press, 2009, pp. 139-140.

[5] DMR (Department of Mineral Resources) Thailand, "Landslide risk assessment and local community in landslide areas in Uttaradit Province, Thailand," (in Thai ), 2011.

[6] P. Kayastha, "Slope stability analysis using GIS on a regional scale," M.Sc. thesis in Physical Land Resources, Vrije Universiteit Brussels, 2006.

[7] DMR (Department of Mineral Resources) Thailand, "Landslide scar data base in Uttaradit Province," 2006.

[8] N. Nilaweera, "Effects of tree roots on slope stability: the case of Khao Luang Mountain area, southern Thailand," Doctor of technical science dissertation, Asian Inst Tech, Bangkok, Thailand, 1994.

[9] J. Fowze, D. Bergado, S. Soralump, P. Voottipreux, and M. Dechasakulsom, "Rain-triggered landslide hazards and mitigation measures in Thailand: From research to practice," Geotextiles and Geomembranes, vol. 30, pp. 50-64, 2012.

[10] D. R. Montgomery and W. E. Dietrich, "A physically based model for the topographic control on shallow landsliding," Water Resources Research, vol. 30, no. 4, pp. 1153-1171, 1994.

[11] Start. (2012). Southeast Asia START Regional Centre [Online]. Available: http://climatechange.jgsee.org/V2 [Accessed: 30 June 2012] 